\title{
Numerical simulation of debris flows
}

\author{
H. Chen and C.F. Lee
}

\begin{abstract}
A key requirement in the assessment of landslide risk in such densely populated urban areas as Hong Kong consists of the prediction of potential runout distance or the extent of the subsequent debris flow. This paper presents a three-dimensional dynamic model of unsteady gravity-driven debris flow. The Lagrangian Galerkin finite element method is used to determine the nodal velocity and depth of soil column elements within the sliding mass, with the momentum and mass conservation mathematically closed within the soil column elements. The numerical solution also features a lumped mass matrix and a volume-weighted procedure. The method of least squares approximation plays a smoothing role which enhances stability and efficiency of the numerical solution scheme. The nodal elevation during sliding is obtained via a dynamic bilinear interpolation of the elevation function for the base of the sliding mass. Furthermore, the accuracy, robustness, and generality of this method are validated by experimental results. Its application to the Shum Wan Road landslide and the Fei Tsui Road landslide, both of which occurred during a heavy rainstorm in Hong Kong on 13 August 1995 and involved fatalities, gives reasonable results in comparison to the field observations. A variety of rheological constitutive relationships have already been coded in the present program to provide flexibility and adaptability in practical applications.
\end{abstract}

Key words: debris flows, three-dimensional dynamic model, runout distance.

Résumé : Une exigence essentielle dans l'évaluation des risques de glissement dans des zones urbaines aussi densément habitées que Hong Kong consiste à prédire la distance potentielle de parcours ou l'étendue de la coulée de débris qui s'en suit. Cet article présente un modèle dynamique tridimensionnel (3D) de coulées de débris gravitationnelles non permanentes. La méthode d'éléments finis Lagrangienne Galerkin est utilisée pour déterminer la vitesse nodale et la profondeur des éléments de colonnes de sol à l'intérieur de la masse en mouvement, avec le quantité de mouvement et la conservation de masse mathématiquement fermées à l'intérieur des éléments de colonnes de sol. La solution numérique comprend également une matrice diagonale de masse et une procédure de volume pondéré. La méthode d'approximation des moindres carrés joue un rôle de lissage qui augmente la stabilité et l'efficacité du processus de solution numérique. L'élévation nodale durant le glissement est obtenue par le biais d'une interpolation bilinéaire dynamique de la fonction d'élévation pour la base de la masse en mouvement. De plus, la précision, la robustesse et la généralité de cette méthode sont validées par des résultats expérimentaux. Son application aux glissements de Shum Wan Road et de Fei Tsui Road - les deux s'étant produits au cours d'un orage de pluie abondante à Hong Kong le 13 août, 1995, et ayant impliqué des pertes de vie - donne des résultats raisonnables lorsque comparés aux observations sur le terrain. Une variété de relations de comportement rhéologique ont déjà été codées dans le présent programme pour fournir de la flexibilité et de l'adaptabilité dans les applications pratiques.

Mots clés : coulées de débris, modèle dynamique 3D, distance de parcours.

[Traduit par la Rédaction]

\section{Introduction}

A debris flow is the gravity flow of soils, rocks, and (or) water mixtures often initiated by a landslide, which consists of processes including initiation, flow, and deposition. Its serious consequences are not only caused by the volume and speed of the displaced materials, but also by its unexpected occurrence. A key requirement in the assessment of landslide risk is the prediction of the accumulation zone, the extent of the hazard area caused by the debris flow. Factors affecting the hazard area of the landslide include the causative mechanism of failure, the characteristics of the slope, the mode of movement, and conditions of the downhill

Received March 12, 1999. Accepted July 16, 1999.

H. Chen and C.F. Lee. Department of Civil Engineering, The University of Hong Kong, Pokfulam Road, Hong Kong, China. slope. Post-failure analyses indicate that movements begin slowly and are followed by a rapid transformation of the soil mass into a viscous liquid (Fleming et al. 1989; Sitar et al. 1992). In addition, a triggering mechanism is required to initiate instability (Lade 1993).

To mitigate and prevent landslide disasters, forecasts of the occurrence conditions and prediction of the accumulation zone of the landslide are necessary both theoretically and practically. A heavy rainstorm can be the triggering event to initiate instability of a slope. Tension cracks, steep loose material, exposed excavation, and poor vegetation may also lead to instability. The methods of predicting kinematic parameters can be roughly grouped into empirical approaches, physical scale modelling, and dynamic modelling. Empirical approaches are developed by reference to actual landslide data and based on proper classification of the modes of landslide movements. Physical scale modelling also has been widely used but is hedged by geometrical 
Plate 1. The Shum Wan Road landslide of 13 August 1995 (two fatalities).

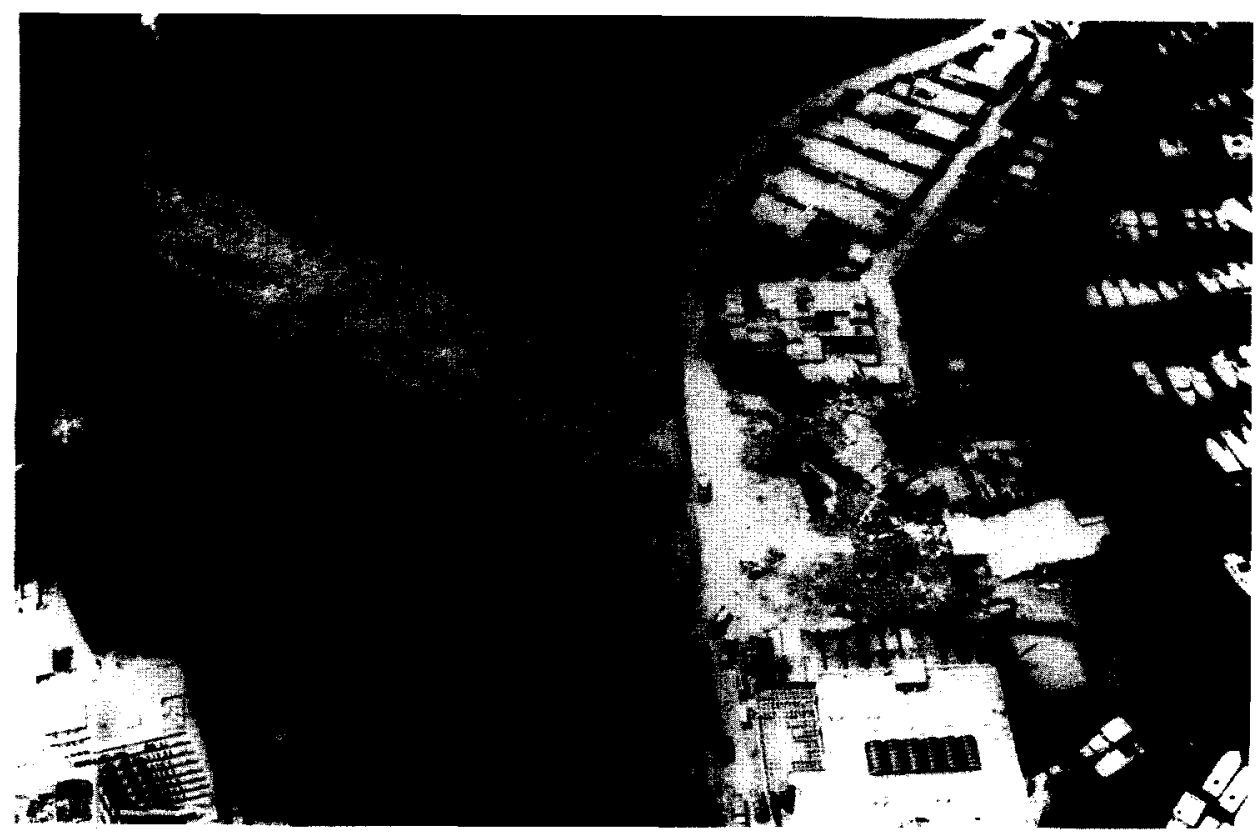

scale effects. Dynamic modelling is categorized into lumped mass models and models based on continuum mechanics. The lumped mass models (e.g., Hutchinson 1986) idealize the motion of the landslide as a single point, which is advantageous for its simplicity. However, these methods are unable to account for internal deformation and simulate the movement of the flow front. The models based on continuum mechanics and associated with a versatile rheological formula have been favored in the predictions of runout distance and relevant parameters. In this regard, analytical solutions (e.g., Iverson 1986; Philip 1991; Hunt 1994) inevitably consist of idealized physical models and field behaviors with considerable simplifying assumptions.

Numerical simulations are generally configured with finite difference schemes in the conventional Eulerian coordinates (e.g., Sousa and Voight 1991; Takahashi et al. 1992; O'Brien et al. 1993; Cao et al. 1996). From practical considerations, the Lagrangian frame is more suitable for this kind of problem because the computational grid is distorted with the highly unsteady moving mass. Research has been focused on two-dimensional (2D) simulations of the descriptions of the shape of the moving mass in the sliding direction (e.g., Hutter and Savage 1988; Hungr 1995), which cannot mimic the characteristics of three-dimensional (3D) landslides. A 3D model using the technique of marker and cell (MAC) was developed by Sassa (1988). Nevertheless, the combination of Lagrangian frame and finite element methods (FEM) has apparently not yet been tried, although it has tremendous applications in other fields for its flexibility and adaptability.

With the advantages of Lagrangian FEM, this study is aimed at developing a 3D dynamic model of unsteady gravity-driven debris flow, simulating the $3 \mathrm{D}$ sliding process with the consideration of factors affecting the accumulation zone caused by the debris flow. The method is validated by experimental results and applied to simulate the Shum Wan Road and the Fei Tsui Road landslides in Hong Kong (Pls. $1,2)$.
Plate 2. The Fei Tsui Road landslide of 13 August 1995 (one fatality).

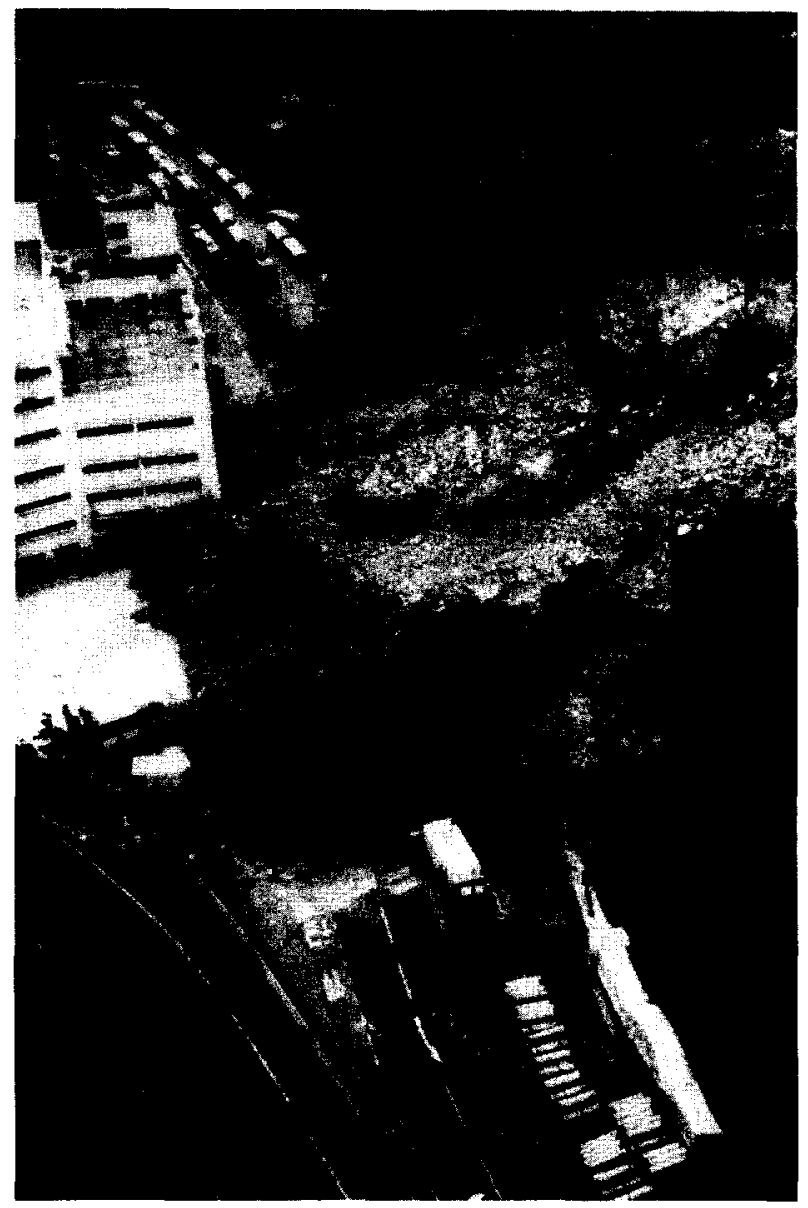


Fig. 1. Diagram of the forces acting on a column.

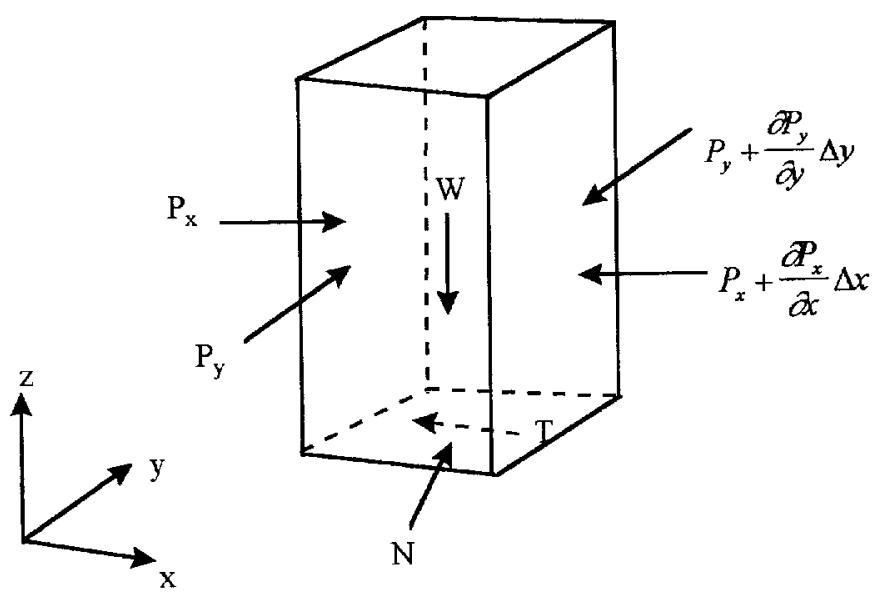

\section{Mathematical model}

\section{Fundamental equation}

When the debris moves, particles which are in close contact will deform relative to one another. In the proposed model, a finite moving mass is represented by a number of columns contacting each other which are free to deform and retain fixed volumes of debris when sliding down a slope assuming constant bulk density. The solution here is referred to fixed Cartesian coordinates $\boldsymbol{X}=(x, y, z)$ in space, with $z$ pointing upward opposite to the direction of gravity. For a typical column, the unit net force acting on the column is denoted as $\boldsymbol{F}$. The 3D momentum equation can be obtained as

$$
\rho=\frac{D U}{D t}=\boldsymbol{F}
$$

where $\rho$ is the bulk density of the sliding materials, $t$ is the time, and $\boldsymbol{U}=(u, v, w)$ is the velocity vector.

For a significant debris flow, the spread is more dominant than the depth in scale. If no overturning occurs, it is reasonable to assume that the momentum equations can be integrated along the $z$ direction within a column. Equation [1] can therefore be reduced to a $2 \mathrm{D}$ depth-averaged equation in $\boldsymbol{X}=(x, y)$ plane:

$$
\rho \frac{D\left(U_{0} h\right)}{D t}=F_{0} h
$$

where $h$ is the depth of a typical column. The subscript 0 denotes the average value of a variable $\Phi$ within a column:

$$
\Phi_{0}=\frac{1}{h} \int_{0}^{h} \Phi \mathrm{d} z
$$

The subscript 0 is omitted hereinafter for brevity.

Zero depth boundary condition is specified along the margin of the moving debris.

\section{Force analysis}

Referring to a moving column as shown in Fig. 1, the unit net force $\boldsymbol{F}$ acting on the column consists of the weight component force of the column $\boldsymbol{W}$, intercolumn force $\boldsymbol{P}$, and basal resistance force $\boldsymbol{T}$. The gravity force is written as $g=$ $(0,0,-\rho g)$. Defining the basal elevation function

$$
\text { [4a] } f=B(\mathrm{x}, \mathrm{y})-z=0
$$

we have the unit direction vector $n$ normal to $f$ as

$$
\boldsymbol{n}=\left(f_{x}, f_{y}, f_{z}\right)=\frac{\left(B_{x}, B_{y},-1\right)}{q}
$$

where the module $q$ is given by $q=\left(B_{x}^{2}+B_{y}^{2}+1\right)^{1 / 2}$. In fact, $q$ is the inclination between the basal elevation function $B(x, y)$ and the horizontal plane, and $B_{x}$ and $B_{y}$ are the first derivatives of $B(x, y)$ with respect to $x$ and $y$, respectively.

\section{Weight force}

The weight force $\boldsymbol{W}$ is obtained by projecting the gravity force $g$ onto the normal direction of the basal elevation. Therefore we have

$$
\boldsymbol{W}=(\boldsymbol{g} \cdot \boldsymbol{n}) \boldsymbol{n}=\frac{\rho g}{q} \boldsymbol{n} \frac{\rho g}{q^{2}}\left(B_{x}, B_{y},-1\right)
$$

where the centered dot refers to the inner product between two vectors.

\section{Intercolumn force}

The remarkable finding of a series of laboratory flume experiments and high-speed ring shear tests (Hungr and Morgenstern $1984 a, 1984 b$ ) demonstrates that the internal friction angles of various materials show no systematic dependence on shear strain rate. The granular material is therefore treated as an incompressible Coulomb continuum described by a constant basal friction angle which is independent of shear rate and solids concentration. The constitutive relationship is in terms of the most widely accepted geomechanical failure criterion, the Mohr-Coulomb yield criterion. The lateral earth pressure ratios in active $\left(k_{\text {active }}\right)$ or passive $\left(k_{\text {passive }}\right)$ states, when a column of materials is being elongated or compressed, are calculated by (Hutter and Savage 1988)

$$
\left.\begin{array}{l}
k_{\text {active }} \\
k_{\text {passive }}
\end{array}\right\}=\frac{2}{\cos ^{2} \phi}\left[1 \pm \sqrt{1-\left(1+\tan ^{2} \delta\right) \cos ^{2} \phi}\right]-1
$$

provided that $\phi$ is the dynamic internal friction angle of the debris mixtures, and $\delta$ is the basal friction angle.

For a debris flow, it is well recognized that the longitudinal stress variations are dominant compared with differential shear. The intercolumn force $\boldsymbol{P}$ on the vertical sides of a column is the difference of the lateral earth pressure acting on both sides of a column as in the Janbu slope stability analysis (Sassa 1988), which in the 3D case can be generally expressed as

$$
\boldsymbol{P}=-\boldsymbol{k} \nabla(\rho g h)
$$

where $\nabla=\left(\frac{\partial}{\partial x}, \frac{\partial}{\partial y}, \frac{\partial}{\partial z}\right)$ is the gradient operator, and $k=\left(k_{x}, k_{y}, k_{z}\right)$ is the anisotropic set of lateral earth pressure ratios. The 
active and passive ratios $k_{x}$ and $k_{y}$ in the $x$ and $y$ directions, respectively, correspond to $\partial u / \partial x_{<}^{>} 0$ and $\partial v / \partial y \geq 0$, and $k_{x}$ and $k_{y}$ are taken as 1.0 for local equilibrium when $\partial u / \partial x=0$ and $\partial v / \partial y=0$, respectively. In the present modelling, the deformation is presumably decoupled in the orthogonal $x$ and $y$ directions, respectively; viz. $\partial u / \partial x>0$ (taken at the column centroid) means the column is elongated in the $x$ direction only, but probably compressed in the $y$ direction if $\partial v / \partial y<0$.

\section{Basal resistance force}

Pointing in the opposite direction of the potential sliding path $s$, the basal resistance force $T$ is a function of different rheological models. The rheological model adopted in the current study is the frictional model in terms of an effective stress, i.e., the resisting shear stress at the base of the flowing mass is a fraction of the total normal stress (Hungr 1995). The bulk friction angle $\phi_{b}$ is defined as

[8] $\tan \phi_{\mathrm{b}}=\left(1-r_{\mathrm{u}}\right) \tan \phi$

where $r_{u}$ is the constant pore-pressure ratio.

The basal resistance force can be derived as

[9a] $\boldsymbol{T}=-(\boldsymbol{g} \cdot \boldsymbol{n}) \tan \phi_{\mathrm{b}} s$

Consistent with the present assumption, $U$ is parallel to $s$, hence

$[9 b] \quad s-\frac{U}{|U|}=\frac{1}{|U|}(u, v, w)$

where the velocity module $|U|=\left(u^{2}+v^{2}+w^{2}\right)^{1 / 2}$. Since the debris particles must not penetrate the base, we thus have $\mathbf{s} \cdot \boldsymbol{n}=\boldsymbol{U} \cdot \boldsymbol{n}=0$, which results in $w=u B_{x}+v B_{y}$.

Therefore, for a given column, the unit net force $F$ in eq. [2] becomes

[10a] $\boldsymbol{F}=(\boldsymbol{g} \cdot \boldsymbol{n}) \boldsymbol{n}-(\boldsymbol{g} \cdot \boldsymbol{n}) \tan \phi_{\mathrm{b}} \boldsymbol{s}-k \nabla(\rho g h)$

with the components in $x$ and $y$ directions

$[10 b]$

$$
\begin{aligned}
& {[10 b] \quad F_{x}=\rho g\left(\frac{B_{x}}{q^{2}}-k_{x} \frac{\partial h}{\partial x}-\frac{1}{q} \frac{u}{|U|} \tan \phi_{\mathrm{b}}\right)} \\
& {[10 c] \quad F_{y}=\rho g\left(\frac{B_{y}}{q^{2}}-k_{y} \frac{\partial h}{\partial y}-\frac{1}{q} \frac{v}{|U|} \tan \phi_{\mathrm{b}}\right)}
\end{aligned}
$$

In conclusion, when the unsteady gravity-driven debris flow is treated as a continuous medium with the assumption of constant bulk density of the displacing mixtures, the fundamental equations describing the flow consist of mass conservation and momentum eq. [2] in which the net force is given by eq. [10a].

\section{Finite element analysis}

The moving mass is discretized into a finite number of quadrilateral elements, and each element is bilinearly transformed into a canonical square in the computational plane $(\xi, \eta)$. At any given instant of time $t$, a given variable $\Phi=$ $\{\boldsymbol{X}, \boldsymbol{U}, h\}$ within an element can be approximated by the shape function $N_{i}$ :

$$
\Phi=\sum_{i=1}^{4} \Phi_{i} N_{i}(\xi, \eta)
$$

in which $N_{i}(\xi, \eta)$ are a family of linearly independent and mutually orthogonal coordinate functions. For an isoparametric finite element, trial function $N_{i}(\xi, \eta)$ is bilinear as

$$
N_{i}=\frac{\left(1+\xi_{i} \xi\right)\left(1+\eta_{1} \eta\right)}{4}
$$

in which $\left(\xi_{i}, \eta_{i}\right)$ are the local coordinates of nodes.

The Jacobian matrix can be obtained by

[13] $\left(\begin{array}{l}\xi_{x} \eta_{x} \\ \xi_{y} \eta_{y}\end{array}\right)=\frac{1}{J}\left(\begin{array}{cc}y_{\eta} & x_{\eta} \\ -y_{\xi} & -x_{\xi}\end{array}\right)$

where $J$ is the Jacobian determinant $J=x_{\xi} y_{\eta}-x_{\eta} y_{\xi}$.

In the weighted residual method, the resulting residual vector of the governing equations is projected onto the subspace of the weighting function which is taken to be the trial function $N_{i}$ under the Galerkin procedure. By requiring a minimum projection, we obtain the discretized formula

$$
\int_{\Omega}\left(\frac{D U h}{D t}-\boldsymbol{F} h\right) N_{i} \mathrm{~d} \Omega=0
$$

where $\Omega$ is the area of integration.

Using the forward Euler scheme for time marching and integrating eq. [14] in the time-independent transformation plane, we obtain

$$
\begin{aligned}
\int_{-1}^{1} \int_{-1}^{1}\left[(\boldsymbol{U} h J)^{n+1}-(\boldsymbol{U} h J)^{n}\right] N_{i} \mathrm{~d} \xi \mathrm{d} \eta & \\
& =\Delta t \int_{-1-1}^{1} \int_{-1}^{1}(\boldsymbol{F} h J)^{n} \mathrm{~d} \xi \mathrm{d} \eta
\end{aligned}
$$

With the midpoint Gaussian quadrature, and bearing in mind mass conservation so that the volume of each element $\left(\mathrm{Vol}_{\mathrm{e}}\right)$ should be kept invariant,

$$
\left(h_{\mathrm{e}} J_{\mathrm{e}}\right)^{n+1}=\left(h_{\mathrm{e}} J_{\mathrm{e}}\right)^{n}=\frac{\mathrm{Vol}_{\mathrm{e}}}{4}=\mathrm{constant}
$$

we thus have

[17a] $M_{i j} \Delta U_{j}^{n+1}=B_{i} \Delta t$

in which

[17b] $\quad M_{i j}=\operatorname{Vol}_{\mathrm{e}} \int_{-1}^{1} \int_{-1}^{1} N_{i} N_{j} \mathrm{~d} \xi \mathrm{d} \eta$

$[17 c] \quad \boldsymbol{B}_{i}=\operatorname{Vol}_{\mathrm{e}} \int_{-1}^{1} \int_{-1}^{1} \boldsymbol{F} N_{i} \mathrm{~d} \xi \mathrm{d} \eta$

[17d] $\Delta U_{i}^{n+1}=U_{i}^{n+1}-U_{i}^{n}$

where the subscript e denotes the average value at an element center, $n$ is the time level, $M_{i j}$ is the time-independent 
consistent mass matrix, $\boldsymbol{B}_{\boldsymbol{i}}$ is the nodal force vector, and the continuity constraint is henceforth released.

To avoid an implicit solution of the algebraic system, $M_{i j}$ is divided into parts:

$$
M_{i j}=M_{i j}^{\mathrm{d}}+\left(M_{i j}-M_{i j}^{\mathrm{d}}\right)
$$

in which $M_{i j}^{\mathrm{d}}$ is the mass matrix lumped onto the diagonal with standard row-sum technique, and $\left(M_{i j}-M_{i j}^{\mathrm{d}}\right)$ is a banded singular matrix which accounts for the local gradient effects. The assembled $M_{i j}^{\mathrm{d}}$ topologically represents the volume controlled by node $i$, i.e., the sum volume of elements sharing this node.

Substituting [18] into [17a] gives

$$
M_{i j}^{\mathrm{d}} \Delta U_{j}^{n+1}=B_{i} \Delta t+\left(M_{i j}^{\mathrm{d}}-M_{i j}\right) \Delta U_{j}^{n+1}
$$

which provides an explicit recursive procedure for solving the consistent matrix. In practice, eq. [19] is solved by a two-step predictor-corrector method:

[20a] $M_{i j}^{\mathrm{d}} \Delta \boldsymbol{U}_{j}^{*}=\boldsymbol{B}_{\boldsymbol{i}} \Delta t$

[20b] $M_{i j}^{\mathrm{d}} \Delta \boldsymbol{U}_{j}^{n+1}=\left(2 M_{i j}^{\mathrm{d}}-M_{i j}\right) \Delta U_{j}^{*}$

in which $\Delta \boldsymbol{U}_{j}^{*}$ is the intermediate velocity residual.

Worth special mention is that the correction step is crucial for unsteady problems. Otherwise spurious dissipation is introduced. Moreover, the volume of an element is unchanged during the motion and hence accumulative error can be avoided. $X^{n+1}$,

When the element vertices displace to new positions at

$$
X^{n+1}=X^{n}+\frac{\Delta t\left(U^{n+1}+U^{n}\right)}{2}
$$

the mean height at an element center can be readily updated by eq. [16]:

$$
h_{\mathrm{e}}^{n+1}=\frac{\mathrm{Vol}_{\mathrm{e}}}{4 J_{\mathrm{e}}^{n+1}}
$$

The nodal heights are then redistributed from the standard least squares approximation:

$$
\text { [23a] } Q_{i j} h_{j}^{n+1}=R_{i}
$$

in which

$$
Q_{i j}=J_{\mathrm{e}}^{n+1} \int_{-1}^{1} \int_{-1}^{1} N_{i} N_{j} \mathrm{~d} \xi \mathrm{d} \eta
$$

$$
R_{i}=\frac{1}{4} \mathrm{Vol}_{\mathrm{e}} \int_{-1-1}^{1} \int_{-1}^{\mathrm{l}} N_{i} \mathrm{~d} \xi \mathrm{d} \eta
$$

and $Q_{i j}$ should also be lumped for efficiency. For engineering concerns, the occupied area of the element on the slope can be computed from

$$
S^{n+1}=\iint_{\Omega} q \mathrm{~d} \Omega=4 J_{\mathrm{e}}^{n+1} q_{\mathrm{e}}
$$

in which $q_{\mathrm{e}}$ is the elemental mean inclination between the slope surface and the horizontal plane.
Therefore, momentum and mass conservation are closed within columns, and nodal velocity and depth can be obtained by the Galerkin FEM. The introduction of lumped mass matrix turns out to be a volume-weighted procedure, whose geometric and physical significance is clearly exhibited. The least squares approximation plays a smoothing role which enhances stability and efficiency of the scheme. The basal elevation function $B(x, y)$ is represented in an unevenly spaced coordinate grid. The nodal elevation during sliding can be obtained through the dynamic interpolation of the basal elevation function $B(x, y)$. Consequently, the element average inclinations are calculated and the sliding path can be predicted after the nodal velocity components have been obtained.

\section{Model validation}

Laboratory experiments were conducted (Huber 1980, quoted by Hutter and Savage 1988) in a $10 \mathrm{~cm}$ wide chute of two straight portions (one inclined, the other horizontal). The angle of inclination varied from $40^{\circ}$ to $60^{\circ}$. The initial profile of the granular mass was $15 \mathrm{~cm}$ in height and $25 \mathrm{~cm}$ in base length. A high-speed camera was set to take a sequence of shots of the sliding process.

In the present computation, the inclination of the chute is taken as $50^{\circ}$, the basal friction angle $\delta=23^{\circ}$, and the dynamic internal friction angle $\phi=29^{\circ}$. The lateral earth pressure ratios in active and passive states are calculated from eq. [6] as $k_{\text {active }}=0.8$ and $k_{\text {passive }}=2.43$, respectively. Comparison is made for time history of the front and rear end positions as shown in Fig. $2 a$, and Fig. $2 b$ shows the sequence of calculated profiles in which the flow depth is exaggerated 10 times. The experiment data were originally presented in a slope-fitted curvilinear coordinate system, which has been transformed to the current Cartesian one. Curves in Fig. $2 a$ indicate that as soon as the granular material moves, the front accelerates quickly, whereas the rear part remains nearly at rest for about three units of dimensionless time. When the front comes to rest, the rear end continues pushing forward toward the front until it eventually stops. The mechanism is in close agreement with experimental observations and the discrepancies between the computed and experimental results are within the experiment error.

\section{Application to landslide cases in Hong Kong}

Landslides have been a continual problem causing heavy loss of life and major property damage in Hong Kong. It is estimated that more than $90 \%$ of Hong Kong's landslides are the direct result of major rainstorm events. On average, a significant landslide event, comprising numerous landslides and appreciable disruption and damage, can be expected to occur once every 2 years. Even though most of the failures are minor and shallow in depth with a volume of usually less than $50 \mathrm{~m}^{3}$, many buildings in Hong Kong are constructed so close to slopes and failures can occur so quickly without prior warning that these failures can have very serious consequences, with loss of life in the most serious cases. To understand the mechanism and calculate the extent of the 
Fig. 2. (a) Time records of front and rear end positions. Experimental data from Huber (1980, as cited in Hutter and Savage 1988). (b) Sequence of calculated profiles.

(a)

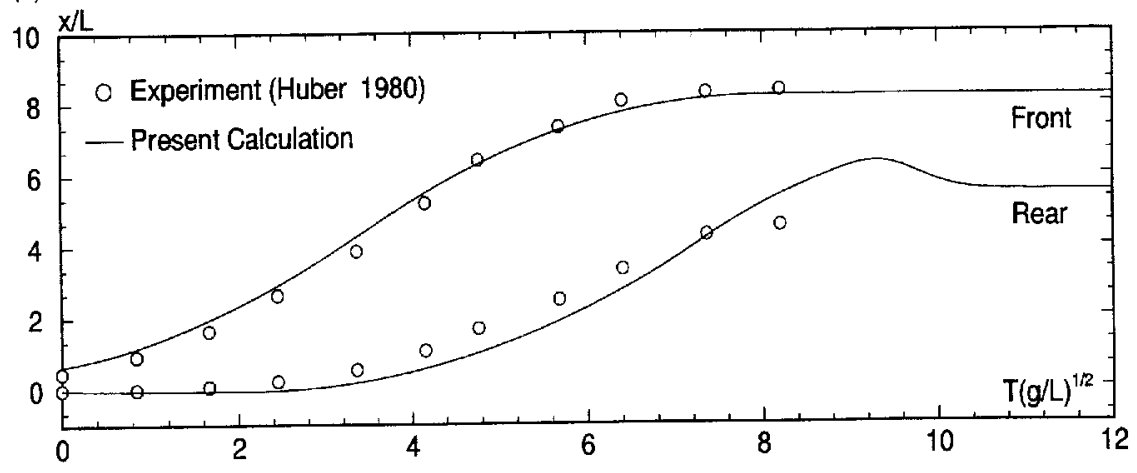

(b)

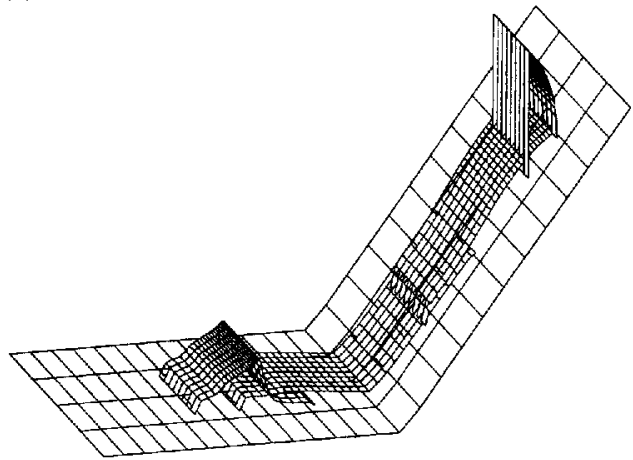

debris flows, the above method is applied to simulate two recent notable landslides in Hong Kong.

\section{Application to the Shum Wan Road landslide}

The Shum Wan Road landslide took place on 13 August 1995 in the southern part of Hong Kong Island. A heavy rainstorm preceded the landslide, which collapsed from the Nam Long Shan Road, crossed the Shum Wan Road, damaged three shipyards and a factory near the seafront, and resulted in two fatalities and five injuries. The landslide released about $26000 \mathrm{~m}^{3}$ of soil and rock and is the largest landslide in Hong Kong over the last 20 years (GEO 1996a).

The landslide resulted in a $70 \mathrm{~m}$ high scarp varying in width from about $50 \mathrm{~m}$ just below Nam Long Shan Road to about $90 \mathrm{~m}$ above Shum Wan Road. The upper part of the landslide surface of rupture was concave in shape and about $12 \mathrm{~m}$ deep below the prefailure ground surface, whereas the lower part was planar. About half of the material released remained on the hillside surface, and the other half was deposited on the reclaimed land which was the site of a temporary industrial area containing a number of shipyards and factories. Some clumps of vegetation were deposited around the outer edge of the debris near the seafront. The extent and profile of the displaced material were determined by topographic surveys as shown in Fig. $3 a$, and a cross section through it is given in Fig. $3 b$.

The released debris comprised mainly very soft or loose fluvial deposit of clay, silt, sand, gravel, and some cobbles and boulders. Prior to the landslide, an area of fill, up to about $5 \mathrm{~m}$ thick, as estimated from aerial photographs covered the upper part of the hillside. The fill generally had a degree of compaction less than $80 \%$ of the Standard Proctor maximum dry density. Soil tests indicate that the clay seam with slickensides has an effective angle of friction $\phi^{\prime}=22^{\circ}$ and an effective cohesion $c^{\prime}=0$. It has been concluded that the presence of weak layers in the ground and the ingress of water during prolonged heavy rainfall principally contributed to the failure.

In the present simulations, the actual topography of the ground before and after the landslide and the mobilized debris are digitized according to the topographic surveys (Fig. 3a). The basal topography is represented by an unevenly spaced coordinate grid system. An unstructured grid and the Lagrangian FEM are used to simulate the shape of the debris to be activated. With reference to Hungr (1998), the bulk friction angle is taken as $\phi_{\mathrm{b}}=20^{\circ}$ in the friction model, and the lateral earth pressure ratios in active and passive states are $k_{\text {active }}=0.8$ and $k_{\text {passive }}=2.5$, respectively.

In the description of the simulated flow process, the deformed mesh of the sliding debris is shown Fig. 4, in which each element deforms differently during sliding, i.e., compression or elongation. The simulated initial projected surface area of the failure mass on the horizontal plane is about $5563 \mathrm{~m}^{2}$ and the volume of the debris is $25384 \mathrm{~m}^{3}$. In total, 823 elements are discretized by 887 nodes within the mobilized debris.

Figures 5-7 show the depth contours of the sliding debris, the sequences of the simulated debris flow, and the time records of velocity and the projected surface area of the sliding debris on the horizontal plane, respectively. These figures demonstrate that the spoon-shaped patch moves continuously and grows larger progressively, i.e., the depth and occupied area of the debris on the sliding base change continuously during the movement. The maximum nodal velocity, about $14.40 \mathrm{~m} / \mathrm{s}$, occurs $9.0 \mathrm{~s}$ after the incipient failure. At $t=$ $15.0 \mathrm{~s}$, the running debris covers the maximum projected surface area, $12838 \mathrm{~m}^{2}$. A computed velocity distribution shows that the maximum nodal velocity takes place when the debris is rushing down near the foot of the hill, whereas the maximum mean velocity appears a little later. The debris flow spreads over the base until the maximum area is reached, and then the extended debris compresses towards its front. It is understood that when the front of the debris flow stops, its rear end still progressively pushes the front. The whole runout process lasts about $33.0 \mathrm{~s}$, and the final deposition area is around $10529 \mathrm{~m}^{2}$. Some of the spoon-shaped debris is deposited in the lower part of the concave scar base, some of the debris releases onto the lower part of the hillside, and some of the debris continues its journey towards the reclaimed land and encounters the factory.

Figure 8 compares the present simulation results with the observed landslide scar (GEO 1996a) and the previous calculation (Hungr 1998). The agreement is fairly good between the present calculated deposition area and the field observation. Regarding the computed scar, our result shows slight underprediction in the sliding direction, but slight overprediction in the spreading direction. Such a phenomenon indicates that there exists a minor discrepancy between the true and digitized topographic landslide ground surface which causes a multidimensional effect. Furthermore, survey 
Fig. 3. (a) Plan of the Shum Wan Road landslide, and (b) section A-A through the landslide (for location see $a$ ). Information shown in the figure is based on topographic survey, geological mapping, and field observations carried out between 13 August and 23 November 1995.

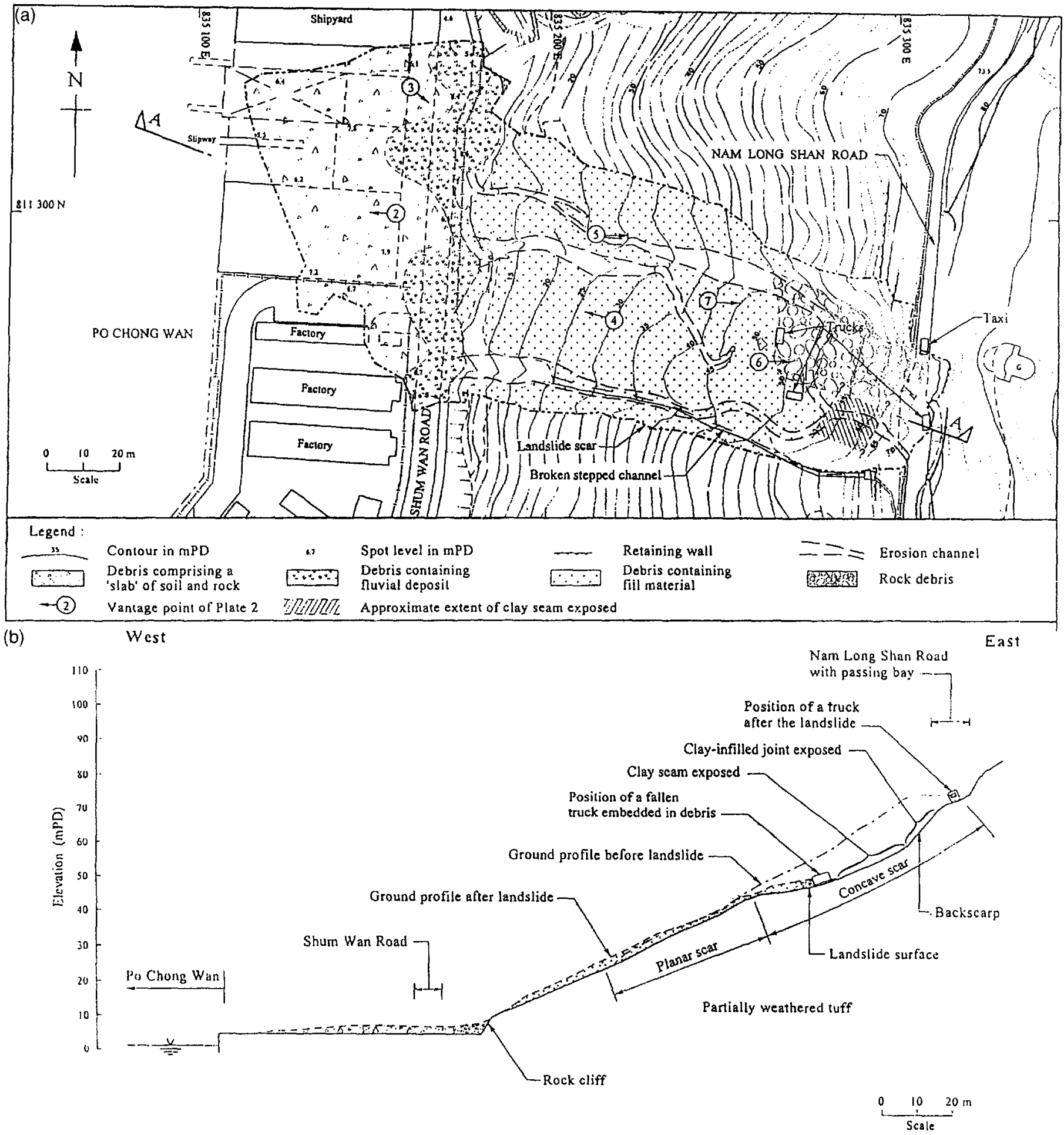

records indicate that cobbles, boulders, and some clumps of vegetation were deposited around the outer edge of the debris near the seafront, whereas the present model regards the debris as a continuous medium and comprehensive soil parameters are taken. With regard to the previous calculation (Hungr 1988), the deposit in the debris fan covers a larger area than indicated by both of the current results and the field records. In addition, its maximum nodal velocity is $17.22 \mathrm{~m} / \mathrm{s}$ and the runout time is $21.88 \mathrm{~s}$, which indicates that the movement in the previous calculation is faster than that of the current modelling, even though the same rheological constitutive relationship and soil parameters were used. 
Fig. 4. Deformed mesh of sliding debris (Shum Wan Road landslide). $V_{\text {mean }}$, mean velocity.
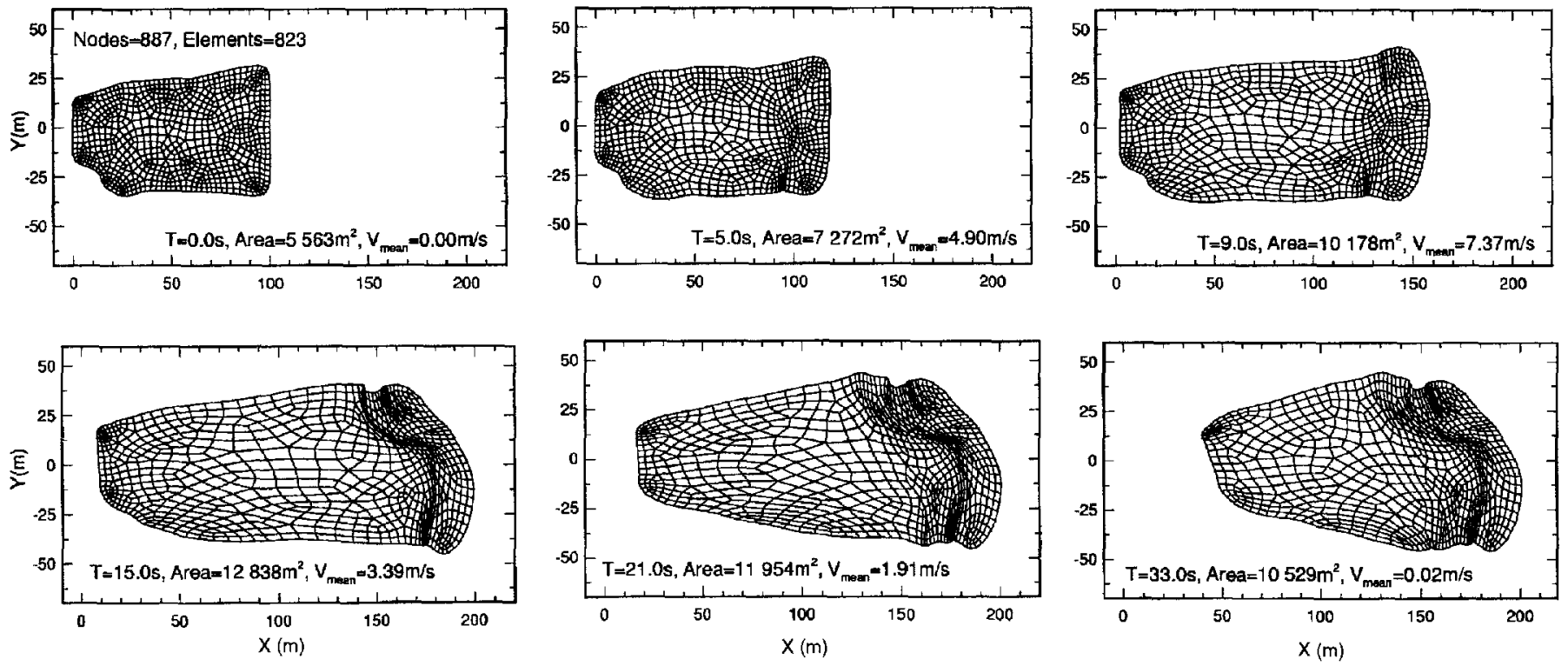

Fig. 5. Depth contours of sliding debris (Shum Wan Road landslide).
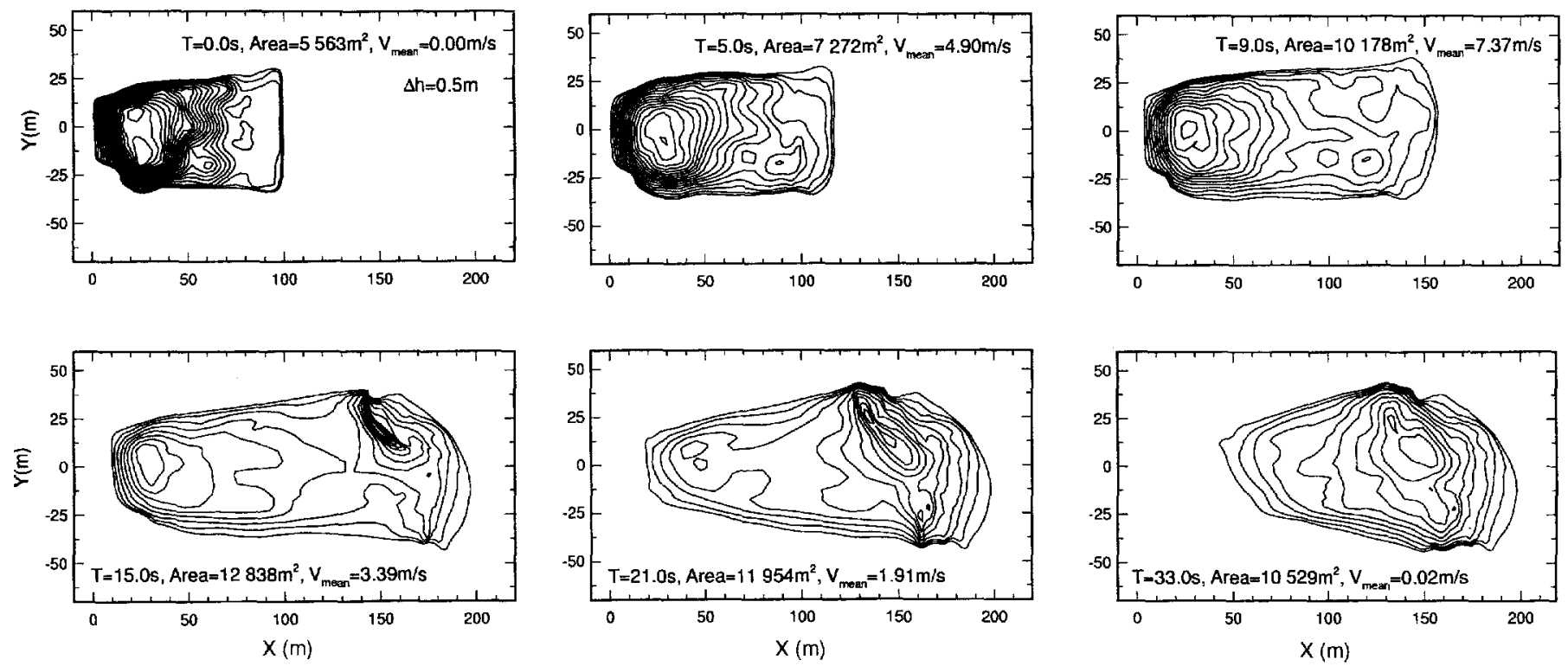

\section{Application to the Fei Tsui Road landslide}

On the same day as the Shum Wan Road landslide, 13 August 1995, a landslide at Fei Tsui Road in Hong Kong buried the road below a cut slope with debris after a heavy rainstorm and caused one fatality and one injury. With an unusual volume of about $14000 \mathrm{~m}^{3}$, it is reported as the largest fast-moving cut-slope failure in Hong Kong over the last decade (GEO 1996b).

The landslide took place in a cut slope with chunam cover on the upper part and exposed rock in its lower part. The Salt Water Service Reservoir with a mass concrete water retaining structure is located to the southeast of the landslide area. About $14000 \mathrm{~m}^{3}$ of debris rushed down the slope, crossed the flat open space and Fei Tsui Road, then deposited onto a playground and the southwestern corner of a church. With an average vertical depth of about $15 \mathrm{~m}$, the landslide formed a scar with a maximum length of nearly $90 \mathrm{~m}$ along the Fei Tsui Road and a maximum extent of $33 \mathrm{~m}$ from the toe of the slope. The maximum horizontal travel distance of the debris was about $70 \mathrm{~m}$, as measured from the crest of the landslide. The landslide scar and a typical cross section $\mathrm{A}-\mathrm{A}$ are given in Figs. $9 a$ and $9 b$, respectively.

The released debris comprised predominantly coarse gravel size to boulder size joint-bound blocks of moderately to highly decomposed tuff together with some other materials, such as asbestos cement pipes, broken pieces of concrete surface channel, broken sections of a masonry wall, and concrete blocks. There was a laterally extensive layer of kaolinite-rich altered tuff dipping approximately to the north at about 10 $25^{\circ}$. Site investigation indicated that the groundwater table 

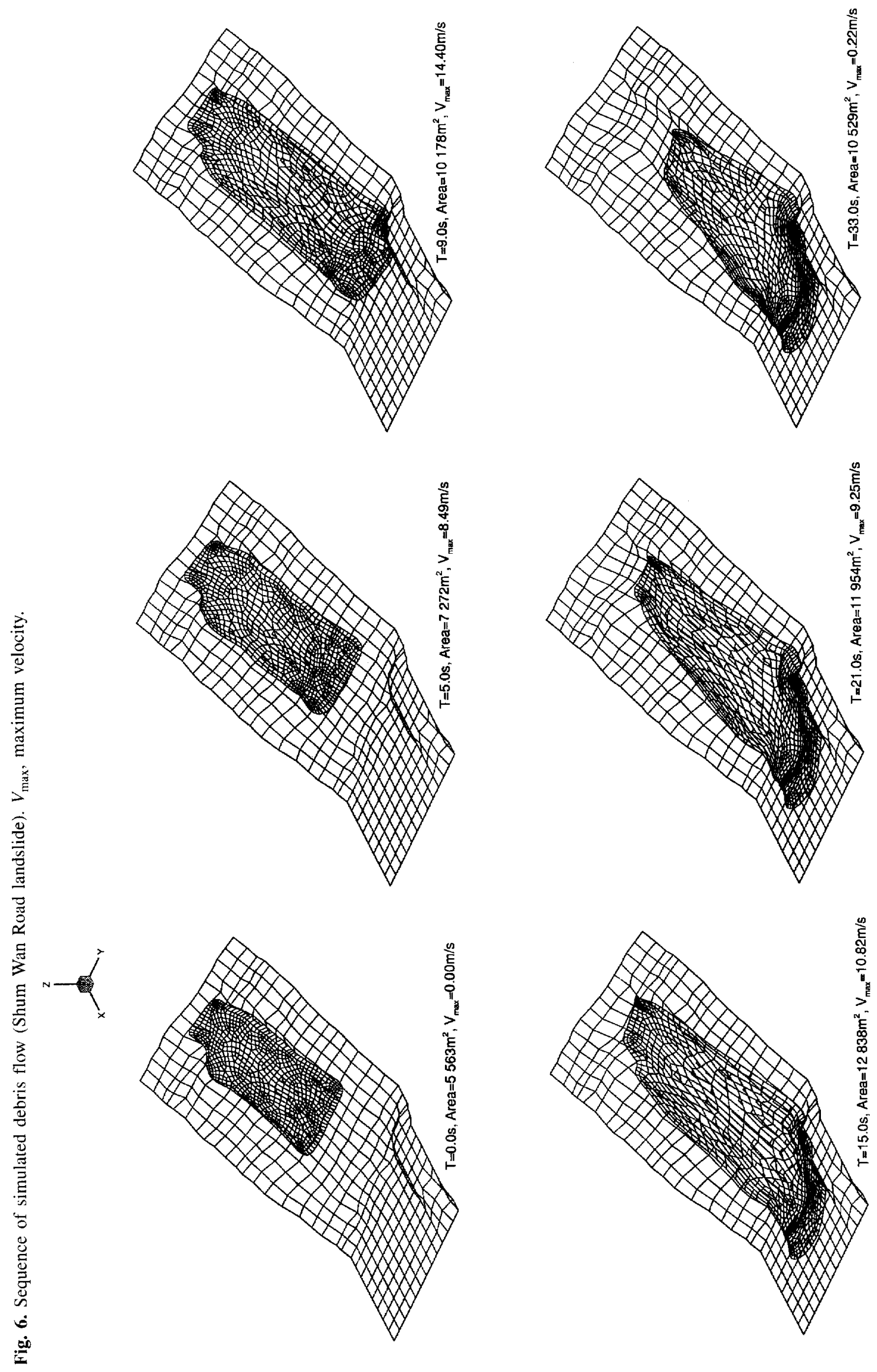

(C) 2000 NRC Canada 
Fig. 7. Time sequence of debris velocity and area (Shum Wan Road landslide).

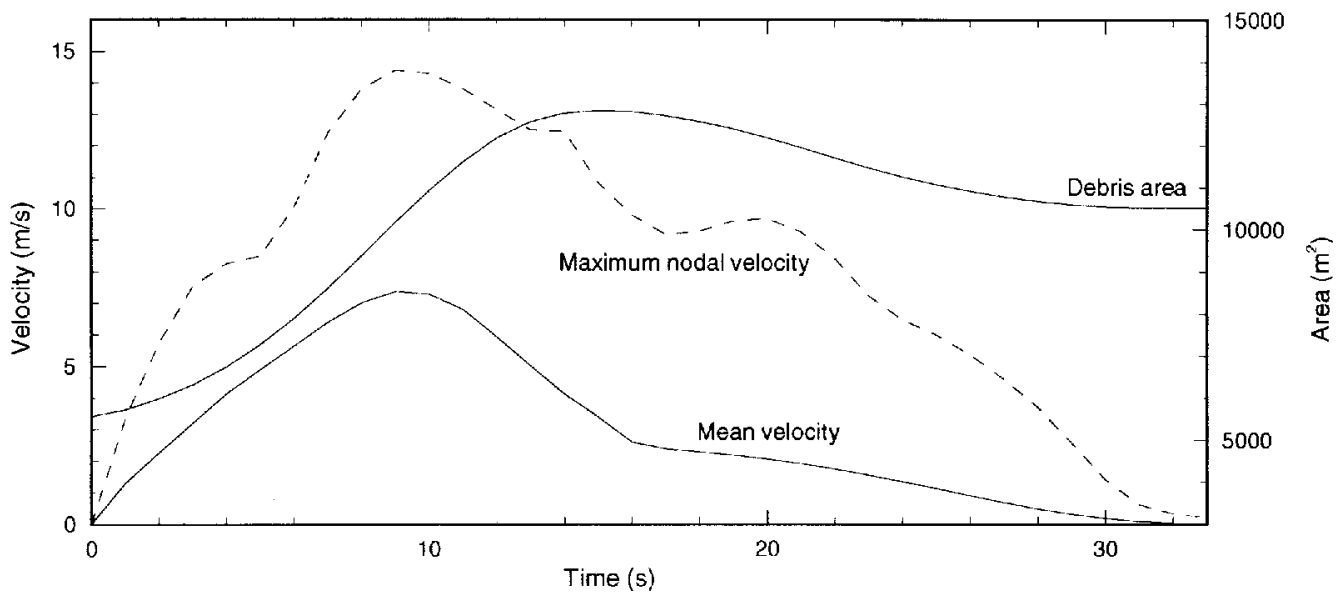

Fig. 8. Final landslide position ( 887 nodes, 823 elements; Shum Wan Road landslide). See Fig. $3 a$ for location of section A-A.

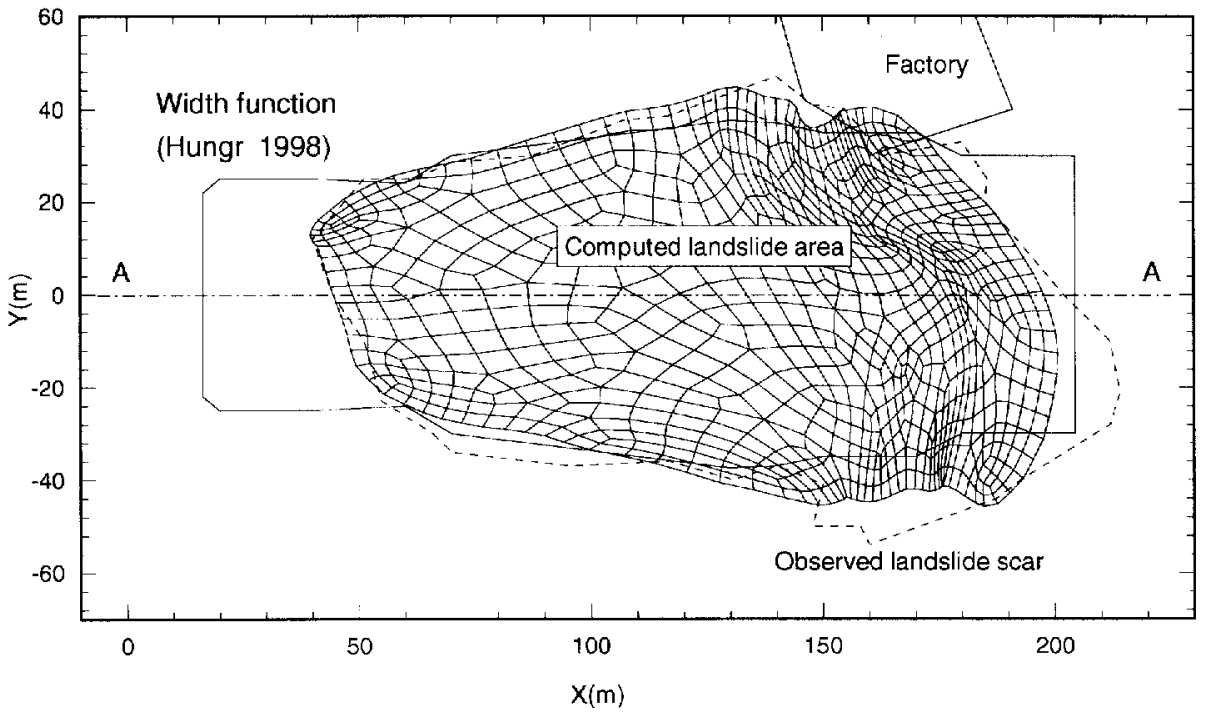

was unlikely to have been above the base of the landslide at the time of failure, and no liquefiable material existed in the sources rock mass or in the path downslope. Direct shear tests to determine the average shear strength of the weathered volcanic joints showed that $\phi^{\prime}=35^{\circ}$ and $c^{\prime}=0$. It is concluded that the 1995 Fei Tsui Road landslide was probably primarily caused by elevated water pressure in an extensive and weak layer in the slope, following the extremely heavy and prolonged rainfall that preceded the failure.

In the numerical simulation of the landslide process, the topography of the landslide ground surface before failure is digitized according to the topographic surveys. The basal function is digitized based on a comprehensive study of the landslide reports, although only section A-A is given here. Hence the mobilized debris can be digitized. The basal topography is also represented in an unevenly spaced coordinate grid system. An unstructured grid and the Lagrangian FEM are used to simulate the shape of the debris to be mobilized. The simulated volume of debris is around $13938 \mathrm{~m}^{3}$ and the initial occupied area on the ground surface is $2659 \mathrm{~m}^{2}$. In total, 524 elements are discretized by 577 nodes within the mobilized debris. In the analysis of the extent of the hazard area, the frictional model is taken as the rheological relationship with the basal friction angle $\delta=22^{\circ}$ and the dynamic internal friction angle $\phi=35^{\circ}$. The lateral earth pressure ratios in active and passive states can be calculated from eq. [6] as $k_{\text {active }}=0.58$ and $k_{\text {passive }}=3.38$, respectively. Bulk friction angle mobilized during failure is taken as $\phi_{\mathrm{h}}=$ $22^{\circ}$ as a dry granular flow.

The calculated sequence of movements described in Fig. 10 three-dimensionally visualizes the entire landslide process. The front of the failure mass accelerates quickly down the slope, followed by a flow-like displacement. After the front of the mass crosses the open flat area of Fei Tsui Road, the rear part of the mass pushes forward to the front until it eventually stops. In Fig. 11, a series of relevant depth contour diagrams exhibit the variation of the debris depth and show that the simulated sliding scar and the final deposition of the sediment on the playground and the corner of a church are in close agreement with the field observations. In the design of preventive measures to minimize dangers due to debris flow, such as guideways, silt-trap dams, cascaded dams, and grid dams, it is necessary to understand the dynamics and velocity fields of the sliding process. This will provide quantitative parameters 
Fig. 9. (a) Plan of the Fei Tsui Road landslide, and (b) section A-A through the landslide (for location see $a$ ). Information shown in the figure is based on topographic survey, geological mapping, field observations, and documentary records. The location of other water mains in the vicinity is not shown in this figure for clarity, and the location of the abandoned 6 in. $(1$ in. $=25.4 \mathrm{~mm})$ diameter water main is not shown because it could not be determined.

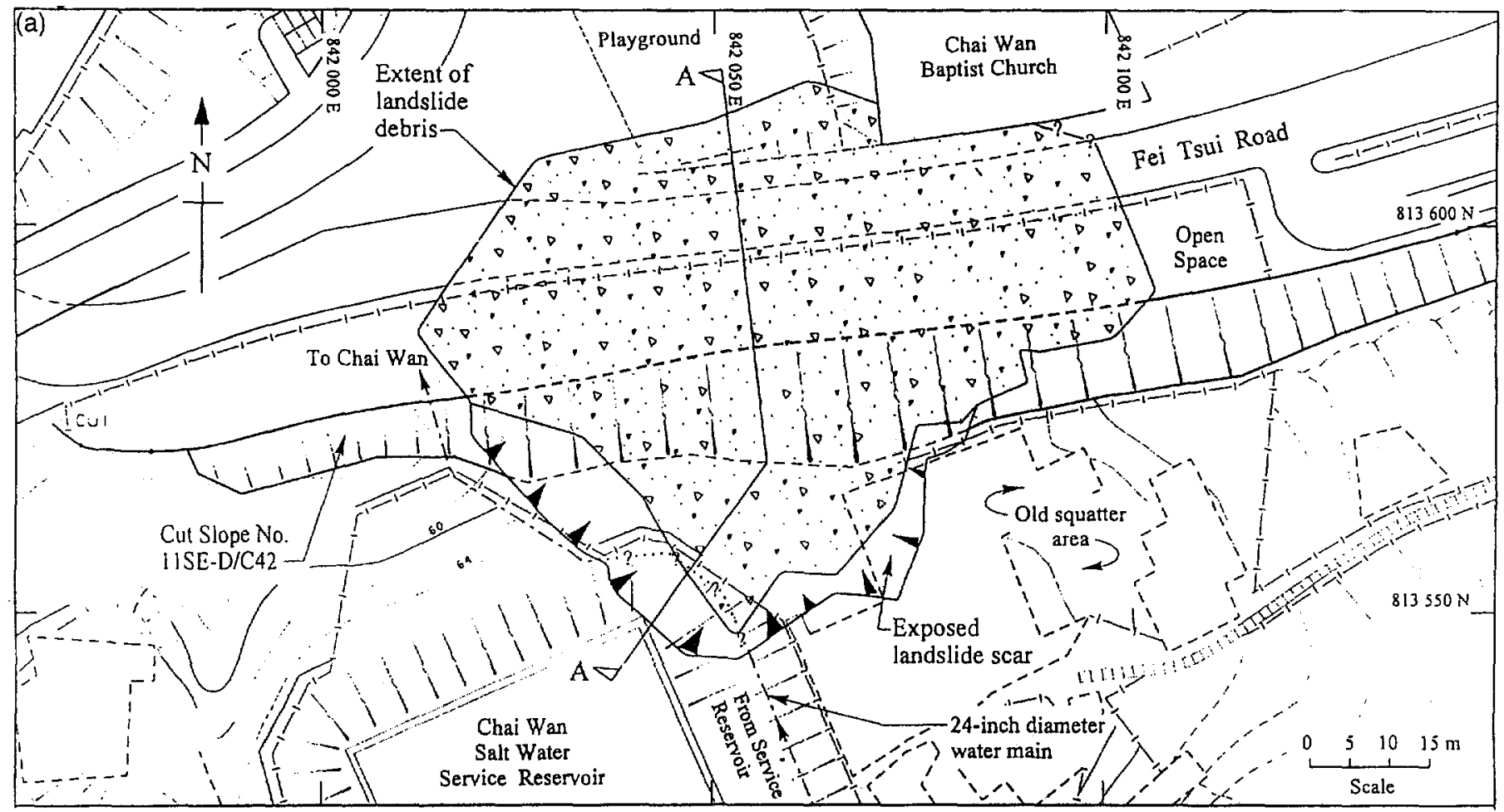

(b) South

North

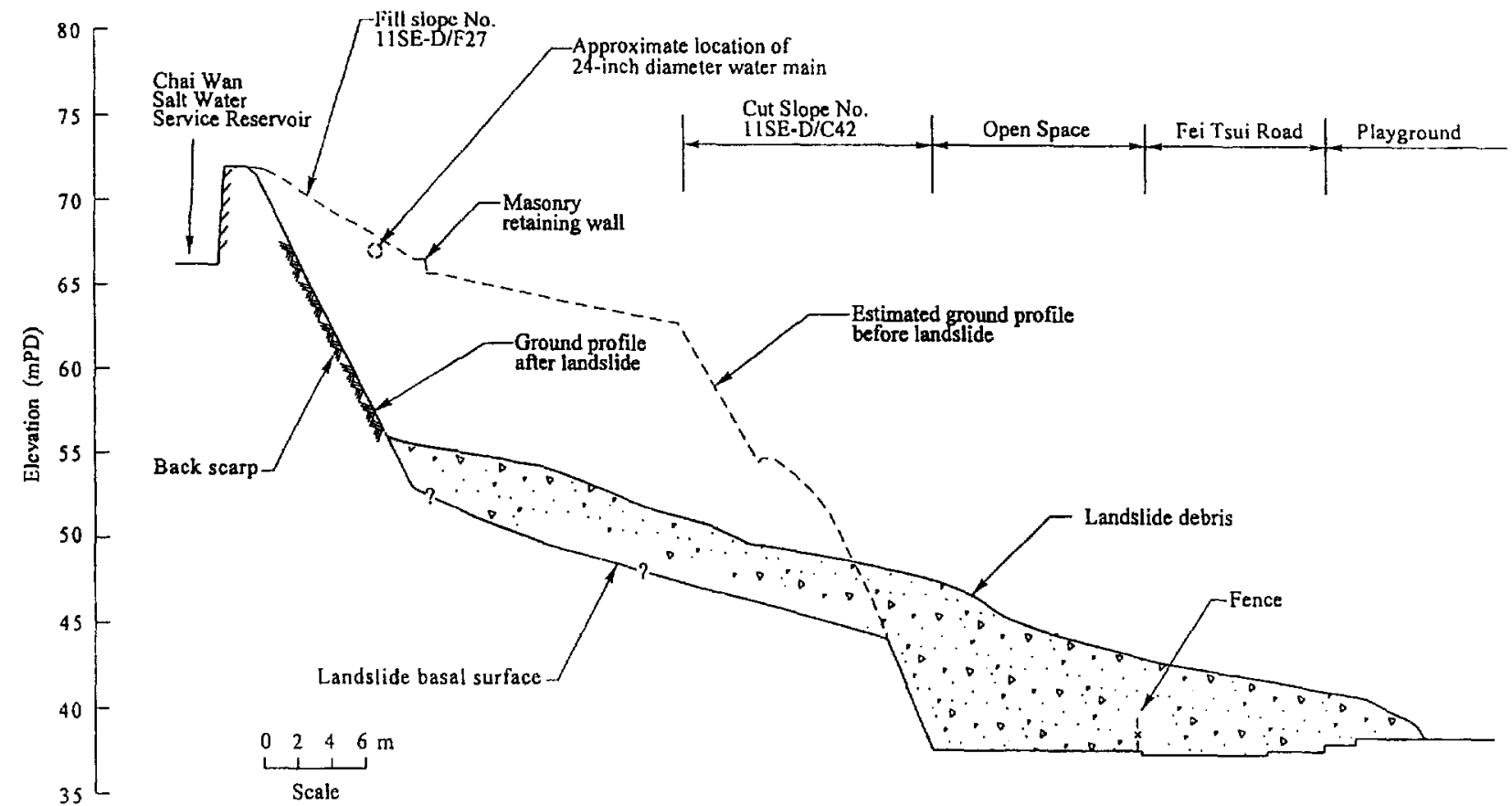

for the design of preventive facilities. In Fig. 12, a series of instantaneous velocity vector field diagrams successfully shows the flow pattern and local velocity variations during the entire movement. In more quantitative terms, Fig. 13 illustrates the time history of the maximum nodal velocity, mean velocity, and occupied surface area on the slope of the sliding debris. It is evident that velocities increase rapidly with a local maximum nodal velocity of $18.54 \mathrm{~m} / \mathrm{s}$ at $t=2.5 \mathrm{~s}$ and a maximum mean velocity of $4.32 \mathrm{~m} / \mathrm{s}$ at $t=3.0 \mathrm{~s}$. After the onset of failure, the sliding mass decelerates to a mean velocity of 

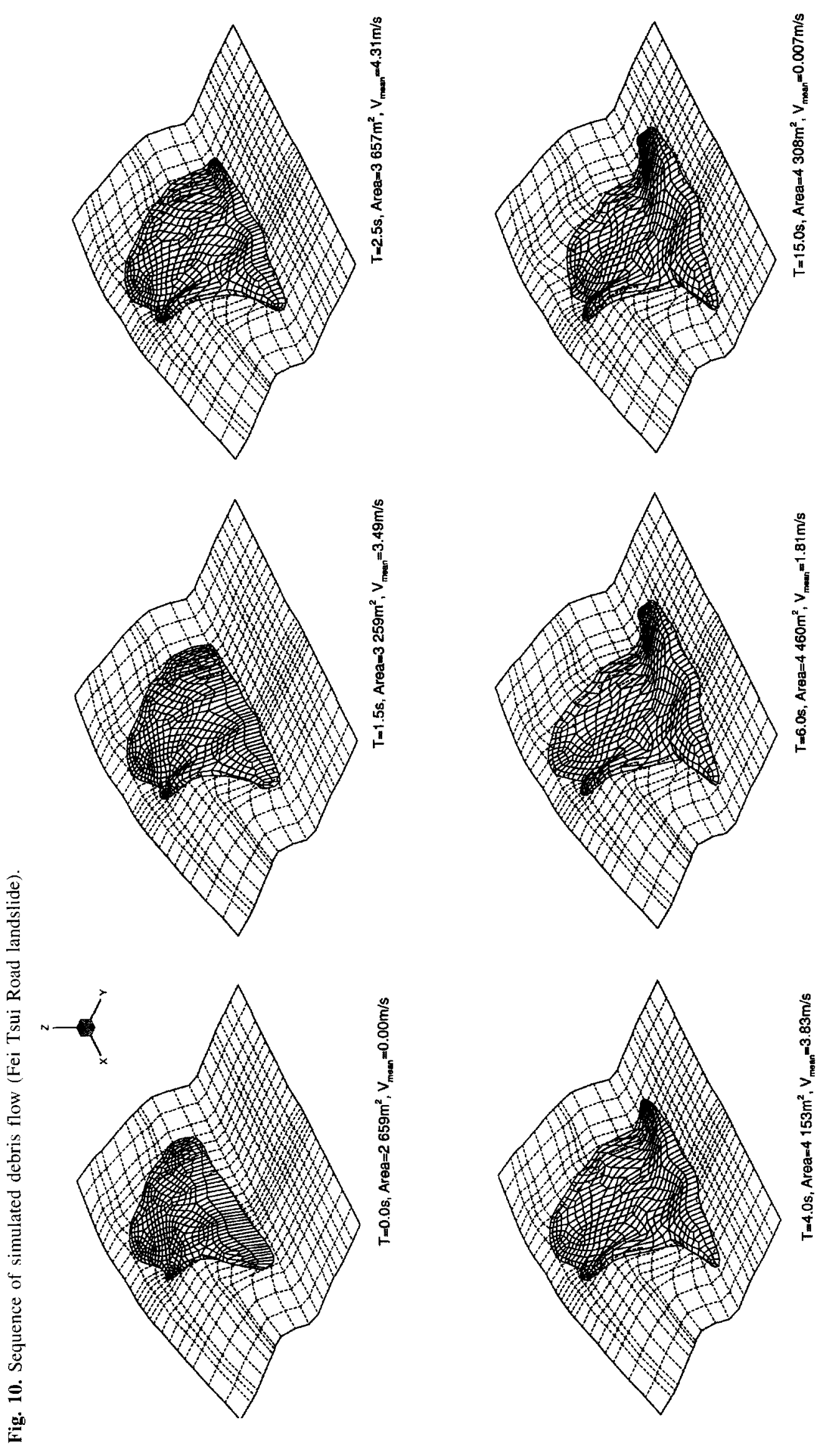
Fig. 11. Depth contours of sliding debris (Fei Tsui Road landslide).
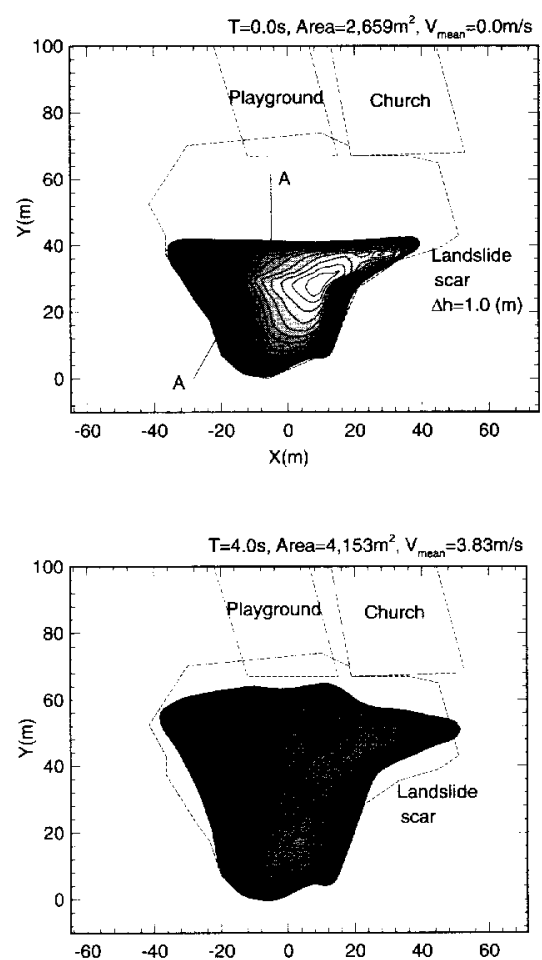
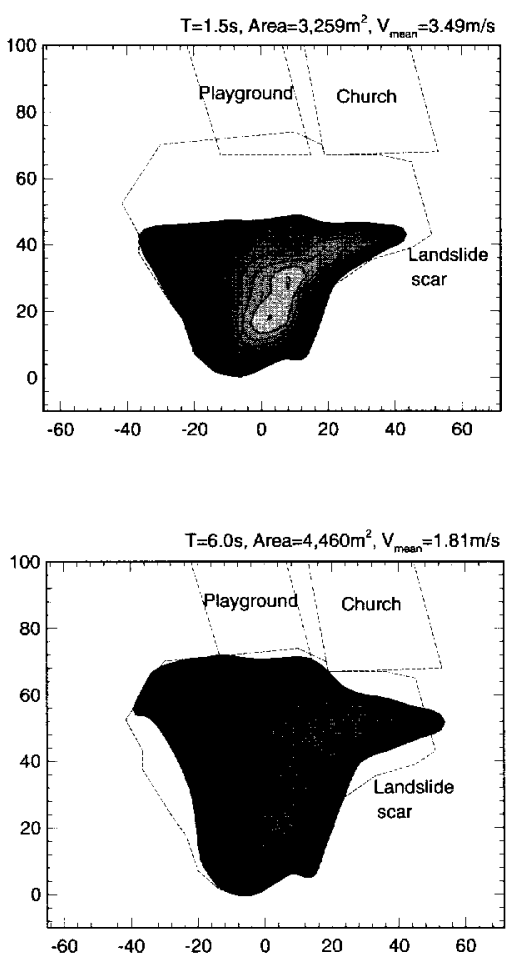
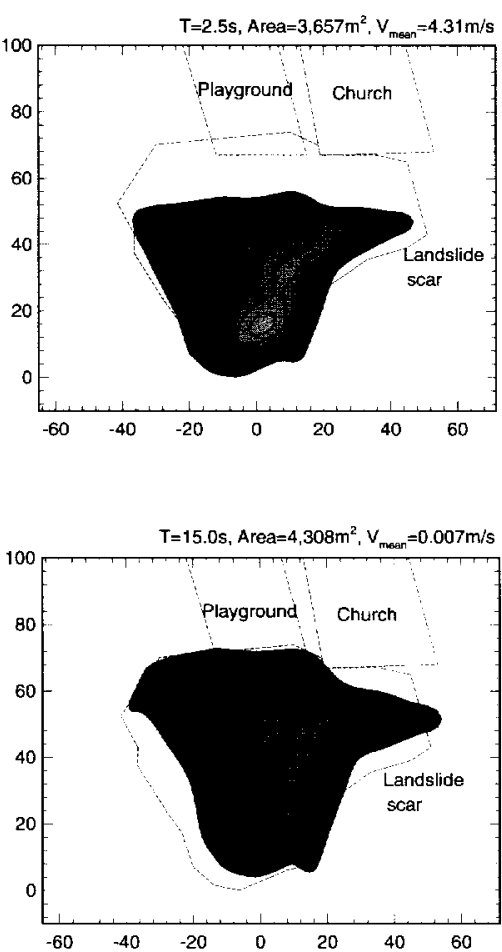

Fig. 12. Instantaneous velocity vector fields (Fei Tsui Road landslide).
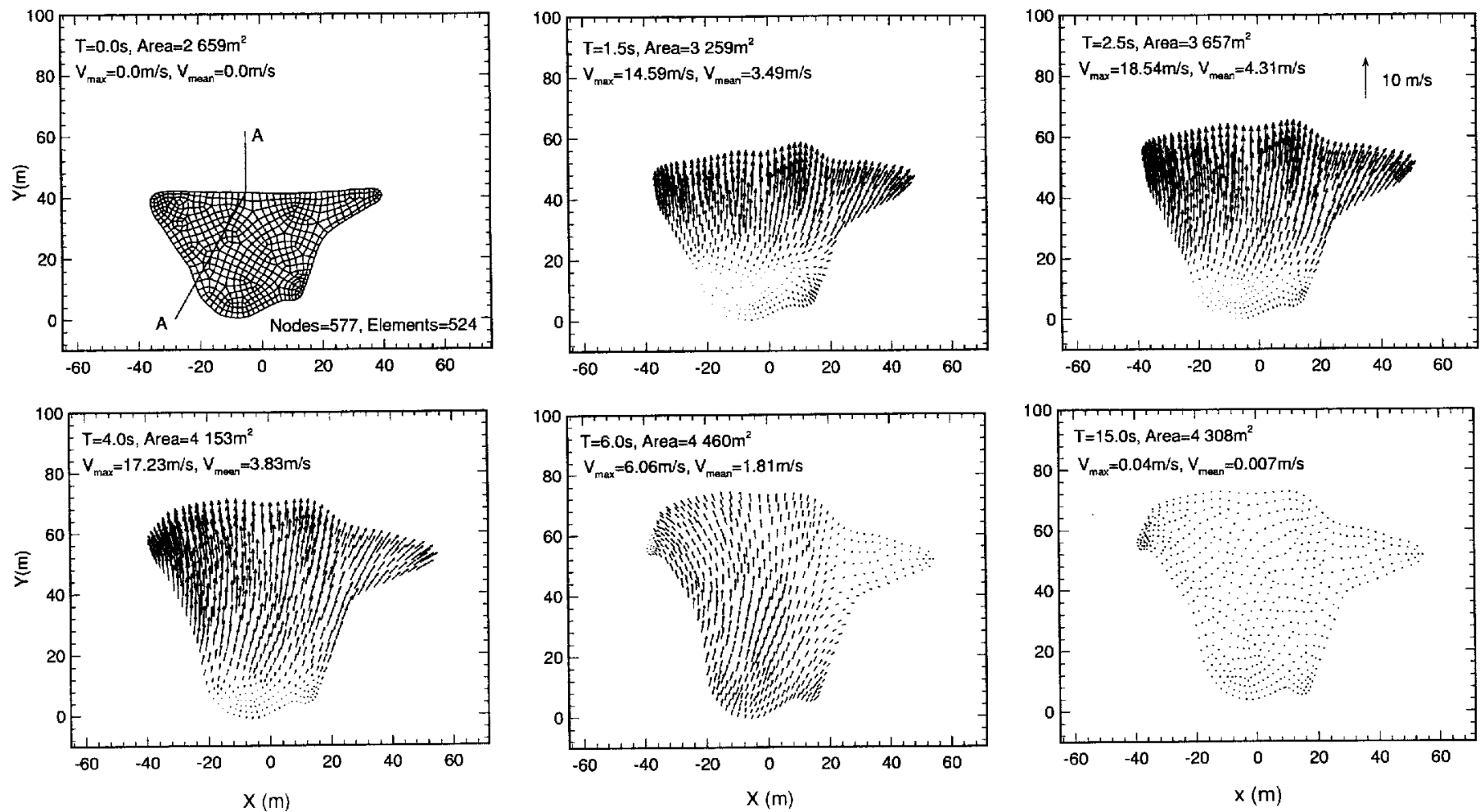
Fig. 13. Time sequence of debris velocity and area (Fei Tsui Road landslide).

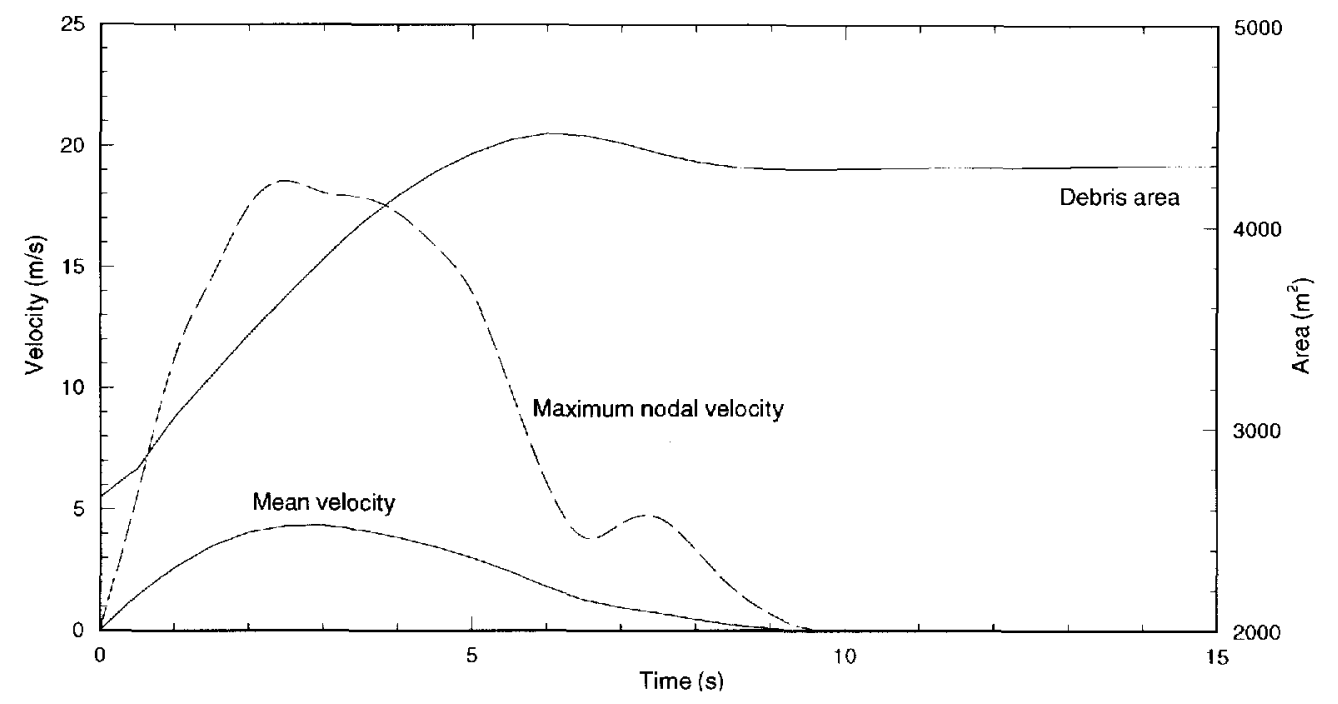

Fig. 14. Temporal evolution of specific energy (Fei Tsui Road landslide).

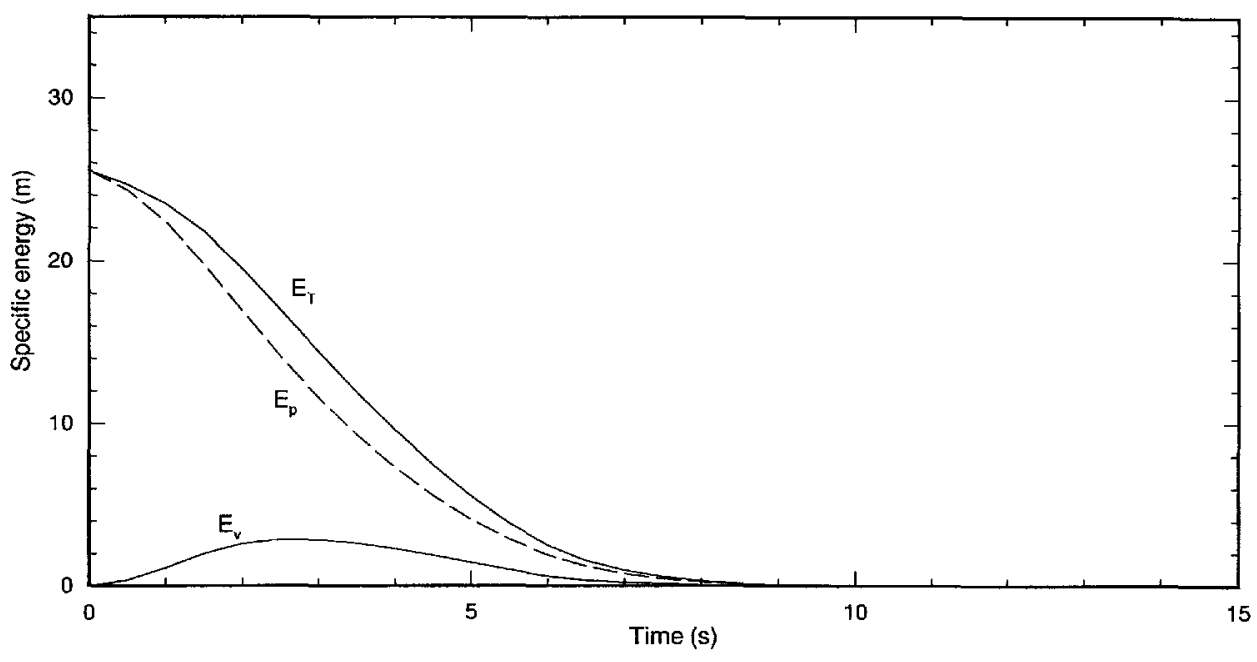

$0.01 \mathrm{~m} / \mathrm{s}$ in less than $10 \mathrm{~s}$. At $t=15.0 \mathrm{~s}$, the mean velocity has a residual value of only $0.007 \mathrm{~m} / \mathrm{s}$, even though the maximum nodal velocity is still $0.04 \mathrm{~m} / \mathrm{s}$. The debris area on the slope has a peak value of $4460 \mathrm{~m}^{2}$ at $t=6.0 \mathrm{~s}$, which occurs later than both the maximum nodal velocity and the mean velocity. It is understood that the sliding mass spreads out after the incipient failure until the mean velocity reduces to a relatively low value. Subsequently, the surface area of the debris increases until the rear part of the debris pushes forward to the front. In the deposition phase, the debris redistributes locally and slowly until it eventually comes to rest. The surface area then reaches a stable value, with a terminal deposition area of about $4308 \mathrm{~m}^{2}$.

To illustrate the energy dissipation caused by friction during movement, the specific potential energy $E_{\mathrm{p}}$ and the specific kinetic energy $E_{\mathrm{v}}$ defined by

$$
E_{\mathrm{p}}(t)=\frac{\int_{\Omega}\left(B+\frac{h}{2}\right) \mathrm{d} \Omega}{\int_{\Omega} h \mathrm{~d} \Omega}
$$

and

$$
E_{\mathrm{v}}(t)=\frac{\frac{1}{2} \int_{\Omega}|U|^{2} h \mathrm{~d} \Omega}{g \int_{\Omega} h \mathrm{~d} \Omega}
$$

are calculated and shown in Fig. 14, in which $E_{\mathrm{p}}(t)$ and $E_{\mathrm{v}}(t)$ are normalized with respect to the total volume, and $|U|$ is the magnitude of the resultant velocity as described in eq. $[9 a]$. In calculating the potential energy, it is referenced to the center of mass of the sliding debris at its final position. The total specific energy $E_{\mathrm{T}}(t)$ is the sum of $E_{\mathrm{p}}$ and $E_{\mathrm{v}}$. Compared with the mean velocity in Fig. 13, it is evident that $E_{\mathrm{y}}$ in Fig. 14 has a synchronic variation with respect to the mean velocity. $E_{\mathrm{p}}$ decreases due to the reduction in elevation, and the work done by gravity is converted into kinetic energy and dissipated by friction. Arising from the rapid varied flow caused by friction, $E_{\mathrm{T}}$ continuously dissipates until the debris eventually stops. It is recognized that the bulk friction angle in the friction model principally accounts for other internal energy dissipation, even though friction is the primary factor 
but not necessarily the only one that leads to the loss of total energy. Figure 14 provides a reasonable overview of the energy variation for this kind of gravity-driven flow.

\section{Concluding remarks}

The landslide, as an accumulation result, is dependent on many factors, such as the sediment properties, volume of the fluid materials, flow situation, and flow theological models, and is sensitive to the topography of the landslide ground surface. Comparative trials show that the sliding velocity of the debris in a smoothed ground surface is greater than that in the actual topography. As expected, the runout time on a smoothed base is less than that on an uneven surface. Even though the shear force among columns is ignored, 3D landslides are still correlated to each other through the variation of the column area. In fact, the occupied area on a sliding base changes continuously with the movement of the debris, which consequently exerts an influence on the debris height and the forces acting on the debris. In other words, oversimplified representation of the topography may modify forces acting on the debris. Therefore, the input data of the topographic ground surface should be accurate to obtain reasonable results because all factors, especially for gravity and frictional forces, are heavily dependent on the inclination of the sliding base.

A 3D dynamic model of unsteady gravity-driven debris flow has been developed. With Lagrangian frame in space and explicit Eulerian integration in time, the momentum and mass conservation are closed within the columns while nodal velocity and depth are obtained by the Galerkin FEM. The use of lumped mass matrix turns out to be a volume-weighted procedure, whose geometric and physical significance is clearly exhibited. The two-step predictor-corrector method avoids spurious dissipation in dealing with the lumped mass matrix. The least squares approximation plays a smoothing role which enhances the stability and efficiency of the scheme. The nodal elevations during sliding are obtained through the dynamic bilinear interpolation of the basal elevation function. Furthermore, the accuracy, robustness, and generality of this method have been validated by experimental results. The application to the Shum Wan Road and Fei Tsui Road landslides gives reasonable results in comparison to the field observations. Different rheological constitutive relationships, which have already been coded in the present program, provide flexibility and adaptability in practical applications.

\section{Acknowledgements}

Financial support of this research by the Research Grants Council (RGC) of Hong Kong and the Jockey Club Charities Trust is gratefully acknowledged.

\section{References}

Cao, J., Ahmadi, G., and Massoudi, M. 1996. Gravity granular flows of slightly frictional particles down an inclined bumpy chute. Journal of Fluid Mechanics, 316: 197-221.

Fleming, R.W., Ellen, S.D., and Algus, M.A. 1989. Transformation of dilative and contractive landslide debris into debris flow - An example from Marin Country, California. Engineering Geology, 27: 201-223.

GEO. 1996a. Report on Shum Wan Road Landslide of 13 August 1995. Vols. 1 and 2. Geotechnical Engineering Office (GEO), Hong Kong Government, Hong Kong.

GEO, 1996b. Report on the Fei Tsui Road Landslide of 13 August 1995. Vols. 1 and 2. Geotechnical Engineering Office (GEO), Hong Kong Government, Hong Kong.

Hungr, O. 1995. A model for the runout analysis of rapid flow slides, debris flows, and avalanches. Canadian Geotechnical Journal, 32: 610-623.

Hungr, O. 1998. Mobility of landslide debris in Hong Kong: pilot back analyses using a numerical model. Report prepared for the Geotechnical Engineering Office, Hong Kong.

Hungr, O., and Morgenstern, N.R. 1984a. Experiments on flow behavior of granular materials at high velocity in an open channel flow. Géotechnique, 34: 405-413.

Hungr, O., and Morgenstern, N.R. 1984b. High velocity ring shear tests on sands. Géotechnique, 34: 415-421.

Hunt, B. 1994. Newtonian fluid mechanics treatment of debris flows and avalanches. Journal of Hydraulic Engineering, ASCE, 120(12): 1350-1363.

Hutchinson, J.N. 1986. A sliding-consolidation model for flow slides. Canadian Geotechnical Journal, 23: 115-126.

Hutter, K., and Savage, S.B. 1988. Avalanche dynamics: the motion of a finite mass of gravel down a mountain side. In Proceedings of the 5th International Symposium on Landslides, Lausanne, pp. 691-697.

Iverson, R.M. 1986. Unsteady, nonuniform landslide motion: 1. Theoretical dynamics and the steady datum state. Journal of Geology, 94: 1-15.

Lade, P.V. 1993. Initiation of static instability in the submarine Nerlerk berm. Canadian Geotechnical Journal, 30: 895-904.

O'Brien, J.S., Julien, P.Y., and Fullerton, W.T. 1993. Twodimensional water flood and mudflow simulation. Journal of Hydraulic Engineering, ASCE, 119(2): 244-261.

Philip, J.R. 1991. Hillslope infiltration: divergent and convergent slopes. Water Resources Research, 27(6): 1035-1040.

Sassa, K. 1988. Geotechnical model for the motion of landslides (Special lecture). In Proceedings of the 5th International Symposium on Landslides, Lausanne, Vol. 1, pp. 37-56.

Sitar, N., Anderson, S.A., and Johnson, K.A. 1992. Conditions for initiation of rainfall-induced debris flows. In Proceedings of the ASCE Geotechnical Division Specialty Conference on the Stability and Performance of Slopes and Embankments, Berkeley, CA, Vol. 2, pp. 834-848.

Sousa, J., and Voight, B. 1991. Continuum simulation of flow failures. Géotechnique, 41(4): 515-538.

Takahashi, T., Nakagawa, H., Harada, T., and Yamashiki, Y. 1992. Routing debris flows with particle segregation. Journal of $\mathrm{Hy}$ draulic Engineering, ASCE, 118(11): 1490-1507. 